\title{
0 impacto do gerenciamento de risco na inovação tecnológica nos serviços de saúde
}

Autores: Juliana Silveira Rodrigues Gonçalo; Milton Colontonio Junior, Marcos Cesar ladocicco, Monica Morgese Alves.

\section{Sobre a instituição}

A BP - A Beneficência Portuguesa de São Paulo é um polo de saúde composto por 4 hospitais e 3 outros serviços de saúde e de educação e pesquisa. Fundada em 1859, a BP possui 8.000 colaboradores, 4.500 médicos cadastrados e oferece serviços de saúde privados e para clientes encaminhados via regulação pelo Sistema Único de Saúde (SUS).

\section{Introdução}

É estimado pela OMS (Organização Mundial da Saúde) que $10 \%$ dos pacientes internados sejam acometidos por algum evento adverso, a metade deles evitável. Entre os fatores que afetam a segurança do paciente estão os riscos que envolvem o uso de equipamentos médico-hospitalares, como a ocorrência de falhas de desempenho, ineficiência nos sistemas de segurança, dentre outros. Desta forma, aumentam-se as exigências de segurança na utilização desses equipamentos nos ambientes hospitalares.

\section{Objetivo}

Este estudo tem como objetivo demonstrar a importância do gerenciamento de riscos e seu resultado no investimento de novas tecnologias para fortalecimento da qualidade e segurança do paciente.

\section{Metodologia}

Trata-se de estudo retrospectivo com utilização do banco de dados do gerenciamento de risco do setor de Qualidade de um hospital de grande porte e alta complexidade na cidade de São Paulo, no período de janeiro de 2016 a junho de 2017.

\section{Resultados}

No período estudado, foram identificadas a ocorrência de 50 eventos adversos graves e sentinelas, do total dos eventos identificados, 12 (24\%) estavam relacionados a falhas com equipamentos médico-hospitalares, tendo como causas principais: falha no manuseio ou na identificação dos sinais de alerta, indisponibilidade ou não utilização de recurso disponível, falta de mecanismo de segurança e equipamento não adequado para a finalidade. Em decorrência do aprendizado gerado com estes eventos, foram investidas 1684 horas homens treinamento e RS 1.822.762,00 reais em ampliação ou adequação do parque tecnológico.

\section{Conclusão}

Fica claro ao analisarmos esses resultados, a importância de uma constante avaliação e atualização das tecnologias disponíveis, o papel importante do gerenciamento de riscos e a interação multidisciplinar para tomada de decisão seja em prioridade de investimentos e/ou dimensionamento correto dos recursos, promovendo a busca contínua dos melhores níveis de qualidade e segurança dos pacientes. 